\title{
Emerging senses from Smart Cities phenomenon
}

\section{SIGRADI2018 TECHNOPOLITICAS \\ xxii congresso da sociedade iberoamericana de gráfica digital 22th conference of the iberoamerican society of digital graphics 07|08|09|novembro|2018 iau usp | são carlos | sp br}

\author{
Bruno Massara Rocha \\ Universidade Federal do Espírito Santo| Brazil| bmassara@gmail.com \\ Katherine Santo Athié \\ Universidade Federal do Espírito Santo| Brazil| katherineathie@gmail.com
}

\begin{abstract}
The paper analyses the emerging senses from the Smart Cities phenomenon, using as background Lemos (2017), Maia (2013), Rozestraten (2016), Söderström, Paache \& Klauser (2014) and evaluating the speeches found in the SmartCity Expo Curitiba. We identified three basic senses: the binary utopia/ficcion, business and informational city, discussed by philosophers such as Foucault (2017), Lévy (2011) e Harvey (2014). The results outline the importance of political role of technology and adverts that it must not be controlled by business. Finally, the paper concludes that the smartest technology is one that opens space to the inclusion of greater human expressivity and subjectivity, not inducing a space of control.
\end{abstract}

Keywords: Smart cities; Digital technologies; Technopolitics;

\section{INTRODUÇÃO}

A tecnologia digital é uma das bases de um fenômeno bastante em voga: as cidades inteligentes, em geral, associadas à expectativa de melhor qualidade de vida e serviços públicos (Cunha et al., 2016). Entretanto, a interconexão cidade e tecnologia digital pode configurar, nesse contexto, um mecanismo de sedução ilusório, como se todas as respostas para os problemas urbanos pudessem ser encontradas na tecnologia em si, configurando um determinismo tecnológico (Lemos, 2017). Nessa perspectiva, pergunta-se: a quem interessa construir as cidades inteligentes? Quem, de fato, beneficia-se com tal modelo tecnológico? Assim sendo, o artigo discute alguns dos sentidos que perpassam a discussão sobre o fenômeno "cidades inteligentes". Em se tratando dos discursos produzidos acerca do tema das cidades inteligentes, notam-se com bastante ênfase valores e interesses corporativos e políticos que adotam o modelo tecnológico como um mecanismo urgente de promoção do bem-estar social, em especial nas grandes metrópoles.

O pensamento de Foucault (2014) nos auxilia na compreensão dos poderes subjacentes ao discurso sobre cidades inteligentes e na análise da subjetividade e das relações de poder nele envolvidas. Segundo o filósofo, os discursos carregam significados que nos permitem analisar as diferenças entre a enorme multiplicidade de valores e interesses que governam as relações sociais, as quais, portanto, são, ao mesmo tempo, políticas. Os discursos podem trazer enunciados carregados de estratégias para exercer o controle e adquirir mais poder sobre determinado tema.

Adotando um discurso de grande penetração social, como a sustentabilidade e a segurança, os interesses corporativos manobram o tema das cidades inteligentes em direção a um universo de grande apelo comercial e vinculação política, mas sem grandes reflexões sobre como, de fato, as tecnologias que as operam podem enriquecer a experiência e a gestão das cidades sob a ótica de seus habitantes.

No caso dos enunciados lançados pelos participantes e organizadores do evento SmartCity Curitiba 2018, percebe-se claramente uma estrutura de discurso molar atrelada aos grandes núcleos coorporativos, empresas privadas e instituições públicas que representam o poder do Estado, configurando um modelo duro de abordagem cujo viés de controle revela mecanismos de manipulação tecnológica (Figura 1). A imagem que se segue é sintomática na representação dos interesses subjacentes ao conceito de cidades inteligentes. Ela foi utilizada para ilustrar parte das apresentações do SmartCity Expo realizado em Curitiba em março de 2018, evento considerado o mais importante para o debate do tema, e que será analisado criticamente neste texto.

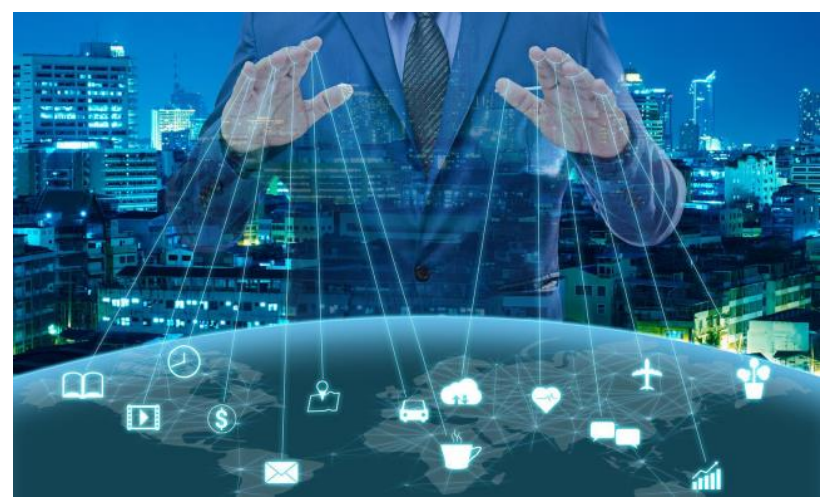

Figura 1: imagem apresentada no SmartCity Expo Curitiba. Fonte: https://ici.umac.mo/wp-content/uploads/

2017/09/where-does-the-internet-of-thinas-come-from.ipa 
Portanto, no que se refere ao tema cidades inteligentes, delineia-se, assim, um campo discursivo tecnopolítico ausente de reflexões de caráter mais molecular este que, ao contrário, implicaria proposições mais sociais, subjetivas, participativas e cooperativas. O objetivo deste texto é desvendar os significados simulados pelo discurso corporativo valendo-se de um pensamento crítico que busca desconstruir o modelo tecnocrático em prol de uma visão sintonizada com as necessidades reais que emergem das cidades e sociedade contemporâneas.

O texto encontra-se organizado da seguinte forma: inicialmente discute a importância da relação cidade $x$ tecnologia, apresenta definições preliminares das cidades inteligentes e em seguida analisa três sentidos que emergem do fenômeno cidades inteligentes: utopia ou ficção, estratégias corporativas e conectividade. Permeando esta organização encontram-se debatidos temas articulados com a tecnopolítica, gestão e planejamento urbanos, experiência da cidade, entre outros.

\section{CIDADES E TECNOLOGIA}

Símbolos proeminentes do período moderno, as cidades vêm experimentando inúmeros desafios na contemporaneidade: sobretudo, os cidadãos lidam com problemas relacionados a mobilidade, violência e infraestrutura, aos quais as soluções apresentadas nem sempre atendem à população de forma igualitária nem no tempo devido.

A demanda pela solução de problemas urbanos é uma urgência e muitos campos disciplinares, mesmo com abordagens diferenciadas, vêm unindo esforços para atendê-la, caracterizando uma tendência interdisciplinar na relação cidade e tecnologias digitais, campo principal de articulação conceitual das cidades inteligentes. Essas conexões podem ser vistas nos laboratórios que concentram instituições públicas, como órgãos do governo e universidades, empresas privadas, institutos de pesquisa e organizações não governamentais.

O Massachusetts Institute of Tecnology pode ser considerado uma referência na articulação destas conexões, como é o caso do MIT Media Lab. Fundado em 1985, o Media Lab reúne diversos grupos que aproximam tecnologia digital, ambiente urbano e cotidiano, para trazer soluções mais coerentes com a complexidade dos problemas urbanos atuais. O Media Lab examina e antevê possíveis contribuições das tecnologias digitais na vida cotidiana, por meio de grupos como City Science, que desenvolve projetos para buscar novas maneiras criativas de conexões entre pessoas, informações e lugares (Maia, 2013). A integridade dos projetos desenvolvidos está articulada com a criação de interfaces digitais e robóticas que podem auxiliar a suprir a demanda por soluções urbanas de alta complexidade, um dos principais desafios das cidades inteligentes.

Nos últimos anos, proliferaram-se plataformas digitais que prometem soluções nesse sentido. A grande contribuição que elas podem dar, no nosso entender, para tornar as cidades mais inteligentes e democráticas é abrir espaço para a interação entre todos os atores sociais, incluindo usuários e poder público em um ambiente de interatividade que favoreça o diagnóstico mais sensível e assertivo dos problemas urbanos.

No contexto brasileiro, o uso dessas plataformas figura em legislações como o Estatuto da Metrópole (2015) e, no Sudeste, destacando o Espírito Santo, no Plano Metropolitano da Grande Vitória (ES) (2017) e no Plano Diretor Municipal de Vitória (ES) (2018), demonstrando sua importância crescente como instrumento de apoio à gestão urbana.

A utilização de plataformas digitais é uma realidade estabelecida e consolidada pelas redes sociais e aplicativos móveis. Em paralelo aos projetos descritos anteriormente, há em curso um movimento mais espontâneo de seu uso para resgatar direitos negligenciados pelas formas oficiais de política representativa. Esse movimento, de caráter emergente e articulado em redes, configura, segundo Márquez et al. (2014), formas importantes de articulação, mobilização e ação tecnopolítica, exemplificando que existe uma apropriação política das tecnologias por parte da população e que governos e pesquisadores devem leválo em conta para a criação de uma base mediadora eficiente e democrática de suporte para cidades inteligentes.

A combinação entre problemas urbanos e tecnologia digital como forma possível de trazer soluções mais velozes, precisas, econômicas e sustentáveis oportuniza múltiplos discursos e interesses sobre cidades inteligentes, formulados por organismos nacionais e internacionais, tais como governos, universidades, mundo corporativo e cidadãos. O uso das tecnologias em contextos urbanos geralmente se associa à expectativa de melhor qualidade de vida e serviços públicos (Cunha et al., 2016), mas pode seduzir as pessoas, configurando um determinismo tecnológico (Lemos, 2017). Por isso, acreditamos haver divergência na compreensão e classificação do que de fato são as cidades inteligentes e o que esse conceito contempla.

\section{CIDADE "INTELIGENTE"}

Na literatura, há múltiplas definições sobre o que seriam as "cidades inteligentes". Os atores envolvidos no desenvolvimento desse fenômeno abordam seus sentidos geralmente no escopo das suas expertises, ideologias e interesses. Além disso, os significados evoluem na mesma velocidade com que surgem as tecnologias de informação e comunicação (TIC), e a partir daí muitos sentidos e entendimentos emergem. No panorama geral, as abordagens costumam considerar o uso das TIC como estratégia e suporte no trato com o ambiente urbano.

A União Internacional de Telecomunicações, segundo o Documento de demonstração de tecnologias para cidades inteligentes, descreve que as

TIC atuam como plataforma para agregar e processar informações e dados e, nesse sentido, viabilizam, por exemplo, compartilhamento da informação e do conhecimento, previsões qualificadas sobre eventos futuros, e integração (Brasil, 2017, p. 14).

A entidade afirma, ainda, que analytics, big data, open data, acessibilidade e gerenciamento inteligente de dados, cibersegurança, banda larga aberta e redes de 
sensores são elementos essenciais ao desenvolvimento das cidades inteligentes. Assim, na contemporaneidade, as TIC não mais são usadas isoladamente, mas programadas para interagir, naquilo que se convencionou chamar "internet das coisas". Há, portanto, um sentido técnico fortemente associado ao conceito de cidade inteligente.

No âmbito acadêmico-científico, o debate sobre o fenômeno das cidades inteligentes, também conhecidas como smart cities, se ampliou nos últimos anos. Autores como Lévy (2011), Söderström, Paache \& Klauser (2014) e Rozestraten (2016) fornecem subsídios para construílas e ou compreendê-las $\mathrm{Cl}$, auxiliando na análise crítica de modelos implementados ou em vias de ser.

A década de 1990 foi o contexto de surgimento da expressão smart cities para conceituar o uso das tecnologias como estratégia em soluções urbanas. No entanto, Rizzon et al. (2017, p. 134) apuram que a expressão não mais está centrada exclusivamente na aplicação de TIC, mas também no envolvimento do cidadão, na governança sustentável, eficiente e participativa. Assim sendo, ainda que as TIC sejam pilares para o avanço e progresso das cidades inteligentes, elas

depende $[m]$ do desenvolvimento contínuo da capacidade de aprendizagem para a inovação e replicação nos processos de gestão da dinâmica urbana (Komninos et al. apud Weiss, Bernardes \& Consoni, 2014, p. 311).

Por isso, a tecnologia, por si só, não basta; deve haver conectividade entre todos os setores para a promoção do desenvolvimento sustentável e, em consequência, se delineie um futuro, de fato, com mais qualidade de vida para a população. Nessa mesma linha, Maia (2013) esclarece que a tecnologia não pode ser determinante justamente porque depende da ação e interação do homem, que dela faz uso para superar os desafios que encontra no mundo.

Panhan, Mendes e Breda (2016) consideram as cidades inteligentes um desdobramento da cidade digital, possibilitando a interação entre organizações e cidadãos. Para tanto, é fundamental que estes estejam inseridos nas iniciativas de compartilhamento de dados sobre o que está sendo proposto para a cidade. Isso revela haver um forte sentido de conectividade associado às cidades inteligentes.

A associação do fenômeno à ideia de mais qualidade de vida e nos serviços públicos também é destacada por Zanella et al. (2014), que, ao tratar a aplicação da internet das coisas na gestão urbana, destacam, ainda, outros benefícios promovidos pelas cidades inteligentes: elas trariam a redução dos custos operacionais urbanos e 0 aumento da transparência, uma vez que as TIC possibilitam coleta e compartilhamento de dados entre cidadãos e governos. Portanto, há também um sentido de eficiência atrelado ao conceito cidades inteligentes. Em síntese, a literatura traz no seu bojo um balaio de conceitos para o fenômeno das cidades inteligentes, que, contudo, se desdobram em muitos outros, mas, que, na atualidade, são perpassados pelos seguintes elementos: TIC, Administração Pública ou governança, inovação de negócios e participação social (Figura 2).

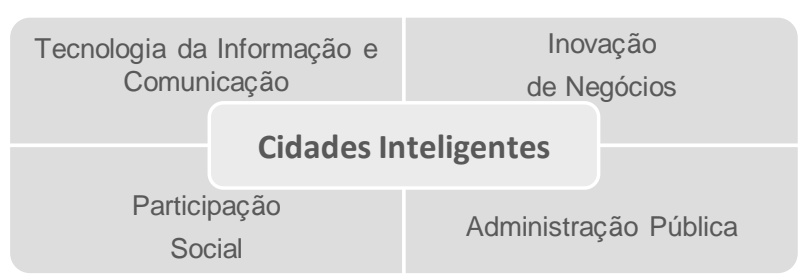

Figura 2: elementos que sintetizam as cidades inteligentes. Fonte: elaboração própria.

Assim, a construção do modelo "cidades Inteligentes" propõe que laços entre o cidadão e a Administração Pública deveriam ser estreitados, bem como os que existem entre empresas de tecnologia e as instituições de governo. De fato, as interações pessoas-cidade-governo também deveriam ser modificadas pelas tecnologias que abraçam essas cidades.

Na visão de Söderström, Paache \& Klauser (2014), nas cidades inteligentes há maior conexão entre cidadão e cidade por meio da tecnologia. Essas conexões ocorrem cada vez mais num ciberespaço de serviços e organizações, caracterizando o que Maia (2013) aponta como um tipo de cidade cada vez menos percebida pela sua aparência física e mais articulada em espaços de informação digitais.

Conforme Gibson, Kozmetzky e Smilor (apud Rizzon et al., 2017), o conceito de cidade inteligente foi formulado principalmente sob a ótica econômica, apoiando-se em estratégias de propaganda e marketing, com a promessa de um ambiente urbano melhor e, por consequência, uma vida também melhor. Este é um sentido problemático em certos aspectos por conta de interesses corporativos alheios às reais demandas urbanas. Isso leva Söderström, Paache \& Klauser (2014, p. 2-4) a sublinharem que o debate sobre esse fenômeno está perpassado por "jogos de linguagem contemporânea", sendo resultado de uma "construção ideológica e como um modelo simplista do urbano", os quais serão discutidos nas próximas seções.

Para finalizar, Lemos (2017) traz contribuições importantes para as definições do conceito, afirmando que, em termos gerais, o adjetivo inteligente refere-se a essa nova sensibilidade performática dos espaços, objetos e ao novo processo digital para organizar a vida urbana.

\section{CIDADE INTELIGENTE: UTOPIA OU FICÇÃO?}

O fenômeno das cidades inteligentes é, para Lemos (2017), uma utopia, pois cria a ilusão de que a tecnologia por si só seria suficiente para resolver os problemas mais graves da sociedade. $O$ autor se preocupa com o que chama de determinismo tecnológico, caracterizado pela mistura de inovação de negócios, discursos tecnocráticos, big data, internet das coisas etc. Sua análise dá a entender que as narrativas oficiais (governo, empresas) estão revestidas pela ideia da cidade inteligente como um produto a ser instalado sobre a cidade real.

A cidade inteligente e a cidade mercadoria estão entrelaçadas em muitas abordagens atuais, para o que alerta Rozestraten (2016), afirmando que, para além das

3 
questões técnicas envolvidas no contexto da tecnologia, há modelos de smarts cities que exploram a oportunidade de negócios e o mercado especulativo de recursos e soluções tecnológicas. Um dos exemplos marcantes nesse sentido é o city marketing (Sánchez, 2009).

Segundo Sánchez (2009), o city marketing é uma tendência mundial. A partir, em especial, da experiência de Barcelona, a autora demonstra como uma cidade pode transformar sua infraestrutura e sua economia a partir de um processo de renovação tecnológica. Barcelona se propôs a substituir o modelo industrial pelo de serviços, para assim se integrar a uma "imensa rede global de conexões" (Leite, 2012, p. 248), com enorme potencial de negócios. Diante disso, cabe refletir que,

sob os intensos processos de promoção e marketing de cidade associados ao projeto político de inserção renovada no mundo, a política urbana de Barcelona é orientada por valores e parâmetros da 'cidade-mercadoria'[...] (Sánchez, 2009, p. 174).

Ao transformar-se em um produto, argumenta a autora, a cidade ganhou novo status no continente europeu, mas sua reificação exigiu deixar para trás aspectos importantes de sua história social e política.

Nesse sentido, se 0 discurso sobre as cidades inteligentes traz a promessa de mais qualidade de vida para a população, é importante atentar para o fato de que esse mesmo mundo digital que conecta também segrega, talvez de maneira ainda mais feroz e sórdida do que as cidades que já conhecemos e que também não são para todos. Por isso, os dispositivos que edificam a nova sociedade não devem deixar de lado parte dela. Muito pelo contrário, os mecanismos tecnológicos e inovações devem ser aproveitados para melhorar especialmente os elos mais frágeis da corrente urbana.

Maia (2013, p. 83) sublinha a crise da noção da cidade que se torna visível por meio das ideias de não-cidade, as quais, em sua percepção, levam à espetacularização da cidade contemporânea, reduzindo-a a um bem de consumo. Outro fator limitante, na visão de Cunha et al. (2016) e Lemos (2017), é que nem sempre as pessoas conhecem as iniciativas que fazem de sua cidade uma cidade inteligente. Este autor considera a falta de participação pública e a invisibilidade de dados como um perigo, uma ameaça ao contrato social mantido entre cidadãos e Estado.

Leite (2012, p. 249), por sua vez, destaca que este seria:

o momento mais propício para irmos além dos governos oficiais, institucionais: [é preciso apostar no] compartilhamento, wiki, centros de informação da cidade, redes de cidades e bairros etc.

Cunha et al. (2016), no entanto, advertem que é a esfera governamental quem lidera o processo de construção das chamadas cidades inteligentes, não sem prescindir da participação dos demais agentes sociais. Igualmente, Lemos (2017, p. 88) compartilha dessa visão, destacando que as cidades inteligentes precisam de financiamento governamental centralizado, o qual ele define como um "protagonista poderoso".
Outro ponto preocupante é destacado por Söderström, Paache \& Klauser (2014, p. 3, tradução nossa), os quais desenvolvem uma crítica à campanha do modelo urbano da cidade inteligente proposto no discurso da IBM como "ponto de passagem obrigatório" na implementação de tecnologias urbanas, afirmando que a campanha massiva da empresa traz em seu bojo a ideia de "cidade concebida como um sistema de sistemas e um discurso utópico que expõe as patologias urbanas e sua cura".

Para esses autores, a campanha da IBM sobre cidades inteligentes está imbuída de uma ficção tecnocrática, na qual as soluções urbanas passam, obrigatoriamente, pelas empresas de tecnologia de informação, como se dados e softwares fossem imprescindíveis para a melhoria da qualidade das cidades. Esse tipo de campanha induz que investimentos públicos priorizem as TIC em detrimento de outras soluções.

Uma das consequências diretas dessa visão tecnocrática é a desconsideração de questões mais elementares e fundamentais da gestão urbana, como a interpretação dos problemas e a perícia na sua resolução, em detrimento de uma visão positivista superficial e de fundo mercadológico. Trata-se de uma ficção bastante perigosa porque, segundo o autor, os problemas não podem ser reduzidos a problemas de dados, mas precisam ser interpretados à luz de debates políticos, sociais e científicos. Nesse modelo mercantil de cidade, asseveram os autores que "as tecnologias urbanas inteligentes [seriam] um ônibus pronto para parar onde quer que os clientes possam ser encontrados" (Söderström, Paache \& Klauser, 2014, p. 20).

Rozestraten (2016, p. 5, tradução nossa) adverte que as inovações propostas em função de um olhar mercadológico voltado para cidades inteligentes são uma versão melhorada do "urbanismo racionalista e funcionalista defendido na década de 1930". Ou seja, trata-se de uma visão mecânica e determinista que se apoia nas inovações trazidas pela tecnologia como resposta mais plausível e segura para os problemas urbanos.

\section{CIDADE CORPORATIVA}

Oportunidades de negócios voltadas para as cidades surgem na mesma velocidade das crises e necessidades urbanas. O fenômeno cidades inteligentes busca nas soluções pautadas em TIC sua marca. Nessa linha, empresas que trabalham com TICS oferecem uma série de soluções e consultorias para governos e, assim, criam uma ponte entre si e as soluções urbanas e um elo poderoso entre instituições públicas e privadas. Atentas, empresas mundiais de TI oferecem o que o cliente (cidades) "precisa", como uma oportunidade de ampliar seus negócios.

A IBM saiu na frente e em 2011 registrou oficialmente a marca "cidades mais inteligentes". A empresa se posicionou no mercado como referência em soluções que envolvem TIC para cidades inteligentes ao se apresentar, segundo Söderström, Paache \& Klauser (2014), como única detentora de tecnologias inteligentes para solucionar a gama de problemas urbanos. O autor assim expõe a visão de cidade utilizada na estratégia de aproximação e marketing da companhia: 
as cidades [...] estão enfrentando os mesmos problemas: crescentes demandas, aperto orçamentário, déficits financeiros, mercados voláteis, complexidades crescentes, poluição, crescimento urbano. A cidade é, em outras palavras, uma 'cidade doente' permeada por uma série de patologias. Para enfrentá-las, os municípios são prejudicados por 'sistemas inadequados para atender às necessidades básicas', 'obsoletos' ou 'tecnologias ultrapassadas', 'custos jurídicos', 'fraudes de benefícios' e 'tempo perdido'. Em suma, a imagem é sombria e as cidades aparecem perto de um colapso fatal (Söderström, Paache \& Klauser, 2014, p. 15, tradução nossa).

Isso demonstra que a IBM recorre a uma visão exageradamente depreciativa e generalizada sobre a condição das cidades atuais como meio para potencializar e justificar sua atuação. Sua linha de serviços e soluções voltadas para as cidades é permeada pelo uso de TIC em áreas como serviços sociais, segurança pública, gestão de impostos, transporte, infraestrutura urbana integrada etc. (Maia, 2013, p. 224).

Assim como a IBM, a Cisco Systems figura entre as maiores empresas de TI do mundo. Sua visão de negócios atual considera soluções para as cidades, sobretudo, nos campos de energia, transporte, educação, gestão pública, saúde, mercado imobiliário, comércio, esportes e entretenimento (Maia, 2013, p. 211). A companhia utiliza em sua estratégia corporativa o fator humano (human network - rede humana), recorrendo à ideia de coletividade como mais um mecanismo de otimização de vendas. Trata-se de uma abordagem corporativa estratégica para aproximar a empresa de seus usuários e construir uma imagem afetiva e mais humanizada para a tecnologia.

As estratégias corporativas para cidades inteligentes incluem a realização de grandes eventos e feiras de negócios, espaços de grande visibilidade que promovem empresas, prestadores de serviços e tecnologias para as cidades. Nesses eventos, podem ser encontradas, por exemplo, empresas de consultoria, construtoras, empresas de transporte, indústrias 4.0 e empresas de segurança. Todas elas emergem no cenário atual como portadoras das soluções necessárias para a construção das cidades inteligentes. Nesse caminho, ocorre o Smart Cities Expo World Congress, uma feira que se apresenta como o maior evento de cidades inteligentes do mundo e cuja versão nacional Smartcity Expo Curitiba aconteceu entre 28/02 e 01/03 de 2018. Em um grande pavilhão, o evento reuniu gestores e empresas com soluções em energia, iluminação pública, sensoriamento remoto, mobilidade, segurança, saúde, entre outras áreas.

O mote do SmartCity Expo em Curitiba foi "a inovação como motor do desenvolvimento econômico", traduzindo claramente o propósito do evento: uma feira de negócios para cidades, na qual parceiros/expositores palestraram sobre seus negócios e as soluções imperiosas que negociam para tornar as cidades inteligentes. Nesse sentido, o evento lançou como proposta a discussão das seguintes temáticas: tecnologias disruptivas, governança, inovação digital e desenvolvimento econômico e futuras cidades sustentáveis. No entanto, tais assuntos foram tratados com superficialidade e de forma fechada, em grupos de interesse predefinidos e com um formato excessivamente midiático.
Por se tratar de um evento-feira de negócios, não há, de fato, discussão sobre os temas, o que se evidencia pela falta de abertura à discussão após as apresentações. Os poucos debates que se sucederam sobre as temáticas propostas foram claramente acríticos e permeados mais por interesses corporativos do que pelas soluções que deveriam emergir do cerne das necessidades urbanas e das pessoas que vivem nas cidades. O controle sobre o discurso imposto pelo ambiente corporativo denota uma das faces de seus interesses: dominar o potencial tecnológico em sua relação com as cidades e, assim, determinar as condições de seu emprego (Foucault, 2014).

Não resta dúvida de que problemas urbanos podem e devem até ser minimizados e diagnosticados por aparatos tecnológicos. Contudo, as cidades devem ser consideradas únicas e reconhecíveis em sua complexidade. Elas demandam muito mais sensibilidade humana e muitos discursos plurais para se compreender as nuances que as cercam e as vulnerabilizam. São oportunas as reflexões de Foucault (2014) para analisar a clara resistência ao debate crítico sobre o tema cidades inteligentes no SmartCity Expo.

Para esse pensador, tais procedimentos revelam um desejo de impor aos indivíduos certo número de regras discursivas, de modo a não permitir acesso à ordem do discurso daqueles que não cumprirem certas exigências ou não forem qualificados para fazê-lo (Foucault, 2014, p. 37). Um dos exemplos mais marcantes desse desejo corporativo de cidade foi o Smart City Laguna, um projeto de condomínio apresentado por um representante da empresa italiana Planet Smart City, em uma seção intitulada Open government and civic engagement (Governo aberto e participação social). A lógica de controle discursivo chama a atenção logo de início, com a convocação para conhecer a "primeira cidade inteligente social do mundo", a qual está em fase de implantação em Croatá, município de São Gonçalo do Amarante (CE).

Tal "cidade" destina-se a 25 mil habitantes, ocupando área de 3,3 milhões de $\mathrm{m}^{2}$. Traz como "pacote de soluções inteligentes": câmeras de segurança, ciclovias, avenida central, pavimentação em blocos de concreto, wifi grátis, aplicativo do empreendimento, sistema de drenagem profundo, instalações de redes de água e de esgoto e água, rede elétrica e iluminação pública solar. Segundo a visão corporativa, estes pacotes contemplam a saída encontrada para atender aos quatro pilares da cidade inteligente: a) pessoas; b) planejamento e arquitetura; c) tecnologias e serviços; e d) meio ambiente (O Smart, 2017).

A denominação "primeira cidade inteligente social do mundo" se revelou completamente vaga e infundada; em nenhum momento foi possível identificar e ou entender o que a visão corporativa considera ser uma "cidade inteligente e social". Promessas vagas e oportunistas de sustentabilidade, segurança, qualidade de vida, redução de custos para os moradores não diferem em nada do discurso empregado pela maioria dos lançamentos imobiliários na atualidade. Ficou evidente o oportunismo do modelo corporativo em divulgar e comercializar um discurso de modernidade associado a um produto de cidade. Cabe destacar que o projeto se instala "no meio do nada", sem conexão alguma com as poucas 
ocupações existentes, configurando um cluster isolado de serviços urbanos capitalizados.

Rozestraten (2016, p. 5) alerta que iniciativas como essas, de novas cidades construídas em terrenos vagos, são "[...] desastrosas do ponto de vista urbano [...] são mais prováveis anti-cidades [...] do que cidades, propriamente". Harvey (2014, p. 156) argumenta que a cidade, mutante por si só, é feita de contrastes de todas as ordens, um espaço em que as diferenças convivem e que, portanto, espaços privatizados, cercados, controlados, vigiados dominados pelo interesse capitalista estão diametralmente opostos à ideia do "comum social, político e habitável" e, dessa forma, em choque com o significado legítimo de cidade.

Com um discurso bastante semelhante, o representante do Instituto das Cidades Inteligentes (ICities) e também coorganizador do evento SmartCity Expo Curitiba André Telles, participou como moderador em uma das sessões paralelas do evento, intitulada Technological disruptions in public services (Tecnologia disruptiva nos serviços públicos). O ICities se anuncia como uma organização social sem fins lucrativos, que desenvolve soluções, produtos, consultorias e projetos voltados para a gestão pública por meio de TIC para cidades inteligentes. Do seu portfólio de clientes constam prefeituras de Curitiba, Inácio Martins (PA), Teresina (PI), Osasco e São José dos Campos (SP), além de outros órgãos instalados no Paraná, como a Justiça Federal, Tribunal de Contas e Ministério Público. Assim como se deu na palestra sobre o condomínio Laguna, o ICities toma posição no evento como um agente de promoção corporativa. Sua participação revela um discurso de estreita relação entre as soluções tecnológicas que desenvolve com o setor público, com um teor excessivamente positivista e sedutor para gestores públicos e também empresários.

A partir dessa análise, o evento SmartCity Expo, considerado o maior do país na abordagem sobre cidades inteligentes, revela que um dos principais discursos que emergem do fenômeno cidades inteligentes é o tecnocrático corporativo. No entanto, salientada aqui essa relação mercadológica, é necessário explicitar um ponto que merece máxima atenção: as necessidades das cidades devem ser vistas além das oportunidades de negócios e dos resultados midiáticos. A consequência mais perversa dessa aproximação corporativa ao tema cidades inteligentes é a criação de uma fantasia de cidade ou o que, nas palavras de Park (apud Harvey, 2014) seria uma utopia urbana conduzida em função das aspirações humanas. Essa fantasia de cidade é fruto do pensamento empresarial que vem tomando o lugar de decisão sobre o planejador urbano.

\section{CIDADE INFORMACIONAL}

No contexto das tecnologias para as cidades, mecanismos de comunicação que possibilitam novas formas de participação popular, acesso rápido às informações, transparência de dados e feitos governamentais ganharam novas configurações e tornaram-se um importante instrumento tecnopolítico para o exercício da cidadania participativa, estando prevista, sobretudo, na Constituição Federal de 1988, a "Constituição cidadã".
As novas formas de acesso público a dados do governo vêm sendo simplificadas com as tecnologias digitais. A acessibilidade a tais dados também está prevista em dispositivos legais, tais como: Lei de acesso à informação (Lei 12.527/2011); Lei da transparência (Lei Complementar 131/2009) e Plano de Desenvolvimento Urbano Integrado da Região Metropolitana da Grande Vitória (Lei Complementar 872/2017). Portanto, legislações federais, estaduais e municipais se ajustam aos novos tempos e trazem em seus corpos o uso de meios eletrônicos como canal de conexão entre sociedade e governo.

O discurso sobre cidades inteligentes também navega na comunicação entre governos e cidadãos a partir do uso das tecnologias e dados dispostos em rede. Gestores, amparados por lei e ávidos como nunca por tecnologia e inovação em seus mandatos, compram ideias cada vez mais bem articuladas por empresas de $\mathrm{TI}$.

Entretanto, ao abordarmos o tema participação social e política, devemos, logo de início, ter clareza de que o papel tecnopolítico dos sistemas de comunicação não está restrito aos suportes digitais oferecidos pelo governo. Com o Marco Civil da Internet (Lei 12.965/2014), foram estabelecidos fundamentos elementares para o acesso à informação digital no Brasil, respeitando a liberdade de expressão, diversidade, colaboração, neutralidade e isonomia da rede, acesso universal e livre concorrência de todos os serviços provedores de informação. Em função disso, todos os cidadãos podem fazer uso de quaisquer sites, redes sociais, provedores de conteúdo e blogs de forma livre e sem controle de ordem maior, para, consequentemente, criar seus próprios mecanismos de articulação política, debate e formação discursiva. Isso se configuraria, portanto, em uma sociotécnica política, que movimenta o ciberespaço e ganha cada dia mais força com as redes digitais. Quanto maior o investimento do governo em promover esse acesso, maior será, a nosso ver, o potencial de se desenvolver inteligências coletivas e tecnopolíticas.

Márquez et al. (2014, p. 342) descrevem a tecnopolítica a partir do seu nascimento, no início do século XXI, quando movimentos políticos diversos se apropriaram das TIC e do ciberespaço para ganhar voz. Os autores assinalam que essas tecnologias, potencializadas por dispositivos móveis e pelas redes sociais, viabilizaram "[...] formas de articulação, mobilização e ação até agora nunca experimentadas". O ciberespaço, segundo Lévy (2011), ao oportunizar a exploração de problemas e debates em larga escala, promove tomadas de decisões coletivas mais democráticas e próximas dos anseios das comunidades envolvidas e independentes em relação aos seus representantes. Esse é, sem dúvida, um dos motores mais importantes da tecnopolítica. Recorrendo a uma metáfora fortemente urbana, o autor utiliza a expressão "ágoras virtuais" para definir o caráter espacialmente agregador do ciberespaço como ambiente de grande potencial para aproximar coletivos heterogêneos. Sem desconsiderar o caráter segregador do ciberespaço, ainda assim a tecnopolítica deve ser considerada instrumento essencial para constituir uma base mediadora das relações entre a coletividade e as esferas de governo, envolvendo política, comunicação, informação e conhecimento (Sierra Caballero apud Bona \& Carvalho, 2017). 
Nesse sentido, o governo brasileiro supervisionou a elaboração do Documento de Referência - Ambiente de demonstração de tecnologias para cidades inteligentes (Brasil, 2017), o qual se constitui em uma espécie de cartilha nos âmbitos do Projeto Ambiente de Demonstração de Tecnologias para Cidades Inteligentes, desenvolvido pela Agência Brasileira de Desenvolvimento Industrial e pelo Instituto Nacional de Metrologia, Qualidade e Tecnologia. Tal documento conceitua a cidade inteligente como:

aquela que, por meio da absorção de soluções inovadoras, especialmente ligadas às Tecnologias da Informação e Comunicação (TIC), ao movimento da Internet das Coisas e ao fenômeno do Big Data, otimiza o atendimento às suas demandas públicas (as quais variam de acordo com a Cidade em estudo), aproximando-se, tanto quanto possível, do estágio tecnológico vigente da humanidade (Brasil, 2017, p. 10).

A partir dessa definição, é importante destacar algumas das "faces da cidade inteligente" (Brasil, 2017, p. 40), que se encontram disponíveis no documento citado, observando especificamente aspectos relacionados à gestão de informação: controle centralizado, integrado e inteligente da informação e das estruturas e serviços públicos; infraestrutura inteligentes de telecomunicações e conectividade; administração pública interativa e inteligente. Da mesma forma, Silva e Bernardes (2015) descrevem que modos de comunicação digital atualizados pela globalização passaram a ser usados pela sociedade no acesso à informação e à participação de forma direta, e não mais mediada pelas mídias tradicionais, como jornais e TVs.

$\mathrm{Na}$ atualidade, as formações discursivas que incorporam terminologias colaborativas parecem ganhar maior audiência e atenção por parte dos setores públicos e privados. Por conta disso, documentos de referencia importantes sobre cidades inteligentes vêm sendo elaborados a partir de múltiplas parcerias privadas, com a colaboração de instituições públicas. Há um esforço claro do governo brasileiro para aplicar e absorver as TIC como meio de otimizar o atendimento às demandas públicas.

O fenômeno aqui discutido aparecia como preocupação para o poder público já em 2013, quando foi criada a Rede Brasileira de Cidades Inteligentes e Humanas, no âmbito da Frente Nacional de Prefeitos. Segundo o Documento Brasil 2030 - Indicadores Brasileiros de Cidades Inteligentes e Humanas (Rede, 2017), a Rede tem como foco troca de informações e experiências voltadas para o progresso e economia das cidades. Com essa perspectiva, reúne pesquisadores, empreendedores e gestores municipais das 350 maiores cidades brasileiras, para traçar objetivos em prol do fenômeno cidades inteligentes. Para a entidade, estas

[...] sustentam sua própria evolução contínua, tendo como metas o bem-estar, a qualidade de vida e o empoderamento do cidadão e das comunidades locais, sustentando seu desenvolvimento em ações, projetos e políticas públicas que promovam de modo igualitário a colaboração entre comunidade, poder público e sociedade civil para a mediação e solução de conflitos e promoção da criatividade local, utilizando, para isso, tecnologias avançadas de interação social e uma infraestrutura tecnológica resiliente, interoperável e transparente de geração e gestão de dados de modo aberto e acessível' (Rede, 2017, p. 18).
A interatividade entre todos os atores sociais por meio de tecnologias digitais distingue a cidade informacional da cidade desconectada. Nessa perspectiva, as tecnologias digitais favorecem 0 acesso, pelos cidadãos, às informações governamentais, oportuniza a participação popular e promove mecanismos de articulação entre si. A coleta de informações é instrumento assertivo nas soluções de demandas urbanas, contudo, deve ser usada com parcimônia e, sobretudo, as respostas e demandas trazidas pelas tecnologias digitais não devem ser vista como únicas. No contexto da cidade informacional, há uma "cidade" sem acesso a qualquer tipo de tecnologia digital e que precisa ainda mais do apoio do Estado. Essa cidade é a cidade desprezada, dos que vivem à margem e em estado de miséria, cada vez mais invisível e afônica.

\section{CONCLUSÃO}

O fenômeno cidades inteligentes carrega no seu cerne uma proposta de cidade conectada digitalmente, cujos serviços e soluções passam, invariavelmente, por grandes empresas de tecnologia digital e seus interesses mercantis. A ideia de economia geral de tempo, recursos naturais e financeiros e melhor performance dos serviços públicos atrelada ao uso das tecnologias e inovações são chamariz para tornar o que seria hoje uma cidade "comum" em "inteligente". Nessa perspectiva, a cidade mercadoria, a cidade de negócios e a cidade informacional emergem como sentidos do fenômeno cidades inteligentes.

A utopia de cidade que se quer fazer crer e comercializar pode levar os cidadãos a serem vítimas das ideologias e interesses empresariais e do governo, alimentados por uma cultura capitalista e envoltas em um marketing sedutor, adotados quase sempre sem reflexão sobre os possíveis desdobramentos na qualidade de vida da própria experiência da cidade. Contudo, surgem novas formas de participação popular, abertas, colaborativas e amplificadas pelo uso de tecnologia digital, cada vez mais simplificadas ao usuário, com a intenção de "humanizar" o modelo de cidades inteligentes. Lévy (2011, p. 64) descreve o uso amplificado das tecnologias pela sociedade como forma "[...] de reunir suas forças mentais para construir coletivos inteligentes e dar vida a uma democracia em tempo real", aspecto no qual as tecnologias dariam voz à sociedade.

Numa perspectiva mais foucaultiana, Vanolo (apud Söderström, Paache \& Klauser, 2014, p. 4) muda o foco dos dados para os cidadãos e discute como o modelo de cidade inteligente pode ser uma poderosa ferramenta disciplinar para moldar "cidadãos inteligentes", que são obrigados a serem tecnologicamente alfabetizados. A "sociedade disciplinar" de Foucault é constituída por poderes adotados pelas instituições como estratégias para disciplinar e confinar 0 pensamento e o comportamento. Desse modo, poderíamos indagar se a voz do povo, envolta por mensagens subliminares interesseiras e absorvida pelos discursos exaustivamente postos nas mídias, teria perdido sua originalidade.

O importante papel político da tecnologia, sobretudo, não deve ficar nas mãos do universo corporativo; a tecnologia mais inteligente é aquela que dá margem para a inclusão e expressão de maior subjetividade, e não para induzir à formação de um espaço de controle. Como assevera 
Lévy (2011, p. 71), "a cidade inteligente tem por finalidade seu próprio crescimento, sua densificação, sua extensão, seu retorno sobre si mesma e sua abertura ao mundo". Logo, não deve ficar à mercê de interesses corporativos, tampouco, deixar de lado a "cidade analógica".

\section{REFERÊNCIAS}

Bona, N. \& Carvalho, G. (2017). Tecnopolítica: a mediação das revoluções atuais. Revista Uninter de Comunicação, 5, 9, 118-123. Recuperado

https://www.cibermov.net/tecnopolitica-a-mediacao-dasrevolucoes-atuais-entrevista-com-francisco-sierra/

Brasil. Ministério da Indústria, Comércio Exterior e Serviços. (2017). Documento de referência Ambiente de demonstração de tecnologias para cidades inteligentes. Recuperado de http://cidadesinteligentes.abdi.com.br/downloads/dl_docume nto_de_referencia.pdf

Constituição da República Federativa do Brasil de 1988. Recuperado http://www.planalto.gov.br/ccivil_03/constituicao/constituicaoc ompilado.htm

Cunha, M. A. et al. (2016). Smart cities: transformação digital de cidades. São Paulo: Programa Gestão Pública e Cidadania, 2016. Recuperado de http://ceapg.fgv.br/sites/ ceapg.fgv.br/files/u60/smart_cities_bra_versao_final.pdf

Foucault, M. (2014). 1926-1984. A ordem do discurso: aula inaugural no Collège de France, pronunciada em 2 de dezembro de 1970/Michel Foucault. Tradução de Laura Fraga de Almeida Sampaio. São Paulo: Edições Loyola.

Harvey, D. (2014). Cidades rebeldes: do direito à cidade à revolução urbana. Tradução de Jeferson Camargo. São Paulo: Martins Fontes - selo Martins.

Lei complementar n. 131, de 27 de maio de 2009. Acrescenta dispositivos à Lei Complementar n. 101, de 4 de maio de 2000, que estabelece normas de finanças públicas voltadas para a responsabilidade na gestão fiscal e dá outras providências, a fim de determinar a disponibilização, em tempo real, de informações pormenorizadas sobre a execução orçamentária e financeira da União, dos Estados, do Distrito Federal e dos Municípios. Recuperado de http://www.planalto.gov.br/ccivil_03/Leis/LCP/Lcp131.htm

Lei Complementar n. 872, de 7 de dezembro de 2017. Institui o Plano de Desenvolvimento Urbano Integrado - PDUI da Região metropolitana da Grande Vitória - RMGV. Recuperado https://planometropolitano.es.gov.br/legislacao-2

Lei n. 12.527, de 18 de novembro de 2011. Regula o acesso a informações previsto no inciso XXXIII do art. $5^{\circ}$, no inciso II do $\S 30$ do art. 37 e no $\S 20$ do art. 216 da Constituição Federal; altera a Lei no 8.112, de 11 de dezembro de 1990; revoga a Lei no. 11.111, de 5 de maio de 2005, e dispositivos da Lei no 8.159, de 8 de janeiro de 1991; e dá outras providências. Recuperado de http://www.planalto.gov.br/ccivil_03/_ato20112014/2011/lei/l12527.htm

Lei n. 12.965, de 25 de abril de 2014. Estabelece princípios, garantias, direitos e deveres para o uso da Internet no Brasil. Recuperado de http://www.planalto.gov.br/ ccivil_03/_ato2011-2014/2014/lei/l12965.htm

Lei n. 13.089, de 12 de janeiro de 2015. Institui o Estatuto da Metrópole, altera a Lei $n^{\circ} 19.257$, de 10 de julho de 2001, e dá outras providências. Recuperado de http://www.planalto.gov.br/ccivil_03/_ato20152018/2015/lei/l13089.htm

Lei n. 9.271, de 22 de maio de 2018. Aprova o Plano Diretor Urbano do Município de Vitória e dá outras providências. Recuperado de http://diariooficial.vitoria.es.gov.br/
ExibirArquivo.aspx?qs=qWdXNT75uq4jT8sAXHV4YcKe8SoL ZJ3dDIfTaxRwv\%2fkTq2\%2f08j9RDCzsKhIVvmB0Zi\%2f2pT 3g5ubRfg3EwY9aOzpu4NH1LpoBJb2FbaHL0XU\%3d

Leite, C. (2012). Cidades inteligentes, cidades sustentáveis: desenvolvimento sustentável num planeta urbano. Porto Alegre: Bookman.

Lemos, A. (2017). Smart cities, internet of things and performative sensibility: brief analysis on Glasgow, Curitiba and Bristol's initiatives. P2P \& Inovação, 3, 2, 80-95. Recuperado http://dx.doi.org/10.21721/p2p.2017v3n2.p80-95.

Lévy, P. (2011). A inteligência coletiva: por uma antropologia do ciberespaço. São Paulo: Edições Loyola, 2011.

Maia, M. R. (2013). Cidade Instantânea (IC). (Tese de doutorado). Universidade de São Paulo, São Paulo, Brasil.

Márquez, A. C. et al. (2014). La tecnopolítica de las multitudes inteligentes: un análisis del \#25S en Twitter. In 15 Encuentro Transdisciplinar MP2P. Recuperado de https://tecnopolitica. net/content/la-tecnopol\%C3\%ADtica-de-las-multitudesinteligentes-un-an\%C3\%A1lisis-del-25s-en-twitter

O Smart Cities Expo World Congress celebra a sua edição no Brasil. Smart City Expo Curitiba. Recuperado de https://www.smartcityexpocuritiba.com/

Panhan, A. M., Mendes, L. de S. \& Breda, G. D. (2016). Construindo cidades inteligentes. Curitiba: Appris.

Rede Brasileira de Cidades Inteligentes e Humanas. (2017). Brasil 2030: indicadores brasileiros de cidades inteligentes e humanas. Recuperado http://redebrasileira.org/arquivos/Brasil_2030_CIH.pdf

Rizzon, F. et al. Smart City: um conceito em construção. Revista Metropolitana de Sustentabilidad, v. 7, n. 3, p. 123-142, set. 2017. Recuperado de http://www.revistaseletronicas. fmu.br/index.php/rms/article/view/1378

ROZESTRATEN, Artur. Doutes, fantaisies et délires: smart cities, une approche critique. Sociétés, n. 2, p. 25-35, 2016.

Sánchez, F. A. (2009). (In)Sustentabilidade das cidades-vitrine. In Acserald, H. (Eds.), A duração das cidades: sustentabilidade e risco nas políticas urbanas (pp. 171-192). Rio de Janeiro: Lamparina.

Silva, E. A. da \& Bernardes, M. de S. (2015). Tecnopolítica e a multidão em rede: do movimento $15-\mathrm{m}$ às manifestações de junho de 2013 no Brasil. In 3. Congresso Internacional de Direito e Contemporaneidade: mídias e direitos da sociedade em rede. Recuperado de http://coral.ufsm.br/congressodireito/anais/2015/3-10.pdf

Smart City Laguna: cidade inteligente social traz um novo conceito de desenvolvimento urbano. (2017). Recuperado de https://fortalezaetc.com.br/smart-city-laguna/

Söderström, O., Paasche, T. \& Klauser, F. (2014). Smart cities as corporate storytelling. City, 18, 3, 307-320. Recuperado de https://s3.amazonaws.com/academia.edu.documents/337591 74/City-

SmartCities.pdf?AWSAccessKeyld=AKIAIWOWYYGZ2Y53U L3A\&Expires $=1529792951 \&$ Signature=DthS1PWGeLqCUCA swyAirnE7Cvl\%3D\&response-content-disposition= inline\%3B $\% 20$ filename\%3DSmart_cities_as_corporate_storytelling.pdf

Weiss, M. C., Bernardes, R. C. \& Consoni, F. L. (2014). Cidades inteligentes como nova prática para o gerenciamento dos serviços e infraestruturas urbanos: a experiência da cidade de Porto Alegre. Revista Tecnológica da Fatec Americana, 5, 1, 310-322. Recuperado de http://www.scielo.br/pdf/urbe/2015nahead/2175-3369-urbe2175-3369007003AO01.pdf

Zanella, A. et al. (2014). Internet of things for smart cities. IEEE Internet of Things journal, 1, 1, 22-32. Recuperado de https://ieeexplore.ieee.org/stamp/stamp.jsp?arnumber $=6740$ 844 